\title{
The Citation Pattern of Brazilian Economists ${ }^{\star}$
}

\author{
- João Ricardo Faria* . Ari Francisco de Araujo JR. ** . Claudio D. ShiKida ***
}

\begin{abstract}
RESUMO
Este artigo estuda os determinantes das citações internacionais dos economistas brasileiros em artigos publicados nas principais revistas domésticas de economia nos anos 1994 e 2004. A pesquisa de economia no Brasil se tornou mais aberta à influencia internacional e mais espalhada geograficamente; os pesquisadores mais especializados e tecnicamente orientados e os tópicos de pesquisa mais diversificados. Entretanto, a pesquisa continua sendo prejudicada pelo favoritismo editorial, refletido no impacto negativo e significante das referências dos autores aos trabalhos dos editores das revistas domésticas sobre as citacoes internacionais. Constatamos que artigos técnicos mais longos sobre tópicos que não sejam sobre história econômica do Brasil têm maior chance de citar a literatura internacional.
\end{abstract}

\section{PalavRAS-CHAVE}

análise de citações, o papel dos economistas e sociologia da economia

\section{ABSTRACT}

This paper studies the determinants of international citations by Brazilian economists in papers published in the top domestic journals in 1994 and 2004. Brazilian research in economics has become more open to international influence and widespread geographically; researchers more specialized and technically oriented and the research topics more diversified. However, Brazil is plagued by editorial favoritism, reflected in the negative and significant impact of references to the works authored by domestic journals editors on international citations. We also find that longer technical papers written on topics other than the economic history of Brazil are more likely to cite foreign literature.

\section{KEY WORDS}

citation analysis, role of economists, sociology of economics

\section{JEL ClassificATION}

\author{
$A / I, A / 4$
}

\footnotetext{
- Acknowledgements: Research assistance of Lucas Lamounier is appreciated. We would like to thank, without implicating, an anonymous referee, P.H. Albuquerque, J.S. Arbache, T. Coupé, M. Léon-Ledesma, A.V. Mollick and Fabio Reis Gomes for valuable comments.

* Department of Economics and Finance, University of Texas Pan American. Address for Correspondence: J.R. Faria, University of Texas Pan American, Department of Economics and Finance, College of Business Administration, I20I W. University Drive, Edinburg, TX 78539-2999, USA. E-mail: jockafaria@hotmail.com.

** Centro de Economia Aplicada e Estratégia Empresarial, Ibmec Minas Gerais. E-mail: arifaj@ibmecmg.br.

** Escola de Governo Prof. Paulo Neves de Carvalho, Fundação João Pinheiro-MG and Centro de Economia Aplicada e Estratégia Empresarial, Ibmec Minas Gerais. E-mail: cdshikida@ibmecmg.br.

(Recebido em julho de 2005. Aceito para publicação em abril de 2006).
} 


\section{INTRODUCTION}

This paper aims at contributing to the growing literature on Brazilian research in economics. This literature has focused on the quantity and quality of publications of Brazilian economists in order to construct productivity and citation rankings of journals, departments and authors. ${ }^{1,2}$ Azzoni (1998) pioneered this literature by analyzing the most cited authors and papers in the Brazilian economic journals, providing a list of "classics" of the Brazilian economic literature. Azzoni (2000) extended this work by assessing the performance of Brazilian departments and journals. The performance of departments was measured through the volume of papers published in domestic journals. The impact of Brazilian journals was assessed through citations in other domestic academic journals (see also Azzoni, 2001).

A couple of articles by Faria (2000) and Issler and Pillar (2002) continued this line of research by analyzing publications in international journals to evaluate Brazilian academic economists and departments. These studies show that the research in economics made in Brazil has very low international penetration, suggesting that poor research standards are widespread in the Brazilian academia.

In a recent paper, Issler and Ferreira (2004) evaluate the performance of Brazilian economists through citations in international journals. They reach two conclusions. The first is that the most productive economists are also the most cited. The second conclusion is that there is a marked difference in the citation performance between Brazilian researchers that prefer to publish in international venues relatively to the ones that submit their work to domestic journals. ${ }^{3}$

This paper deals with the same subject as Issler and Ferreira (2004), however, instead of analyzing the citations of Brazilian economists by the international literature, it investigates the way Brazilian economists cite the foreign literature. Specifically, this paper studies the citation practices of Brazilian researchers in articles published in the top Brazilian economic journals ${ }^{4}$ in two different years, 1994 and 2004. The paper

1 The same trend is verified internationally where rankings of journals, departments and economists mushroomed over the past decade. See, among others, Garcia-Castrillo et al. (2002) and Coupé (2003) for worldwide rankings, for specific countries and regions we have: U.S. (Scott and Mitias, 1996, and Dusansky and Vernon, 1998), Canada (Lucas, 1995), Australia (Pomfret and Wang, 2003), Asia (Jin and Yau, 1999), and Europe (Kalaidizidakis et al., 1999). The rankings' methodologies are themselves object of controversies (e.g., Thursby, 2000, and Tombazos, 2005).

2 Rocha and Machado (2003), in a different line of research, show that economic performance of universities in Brazil is positively related to academic-pedagogic performance.

3 The referee points out that in some cases articles are referred in the literature due to their errors. Therefore they are cited because of its bad quality. However, citations are widely used and recognized as a proxy of impact, signaling quality (see Faria, 2006).

4 The Brazilian journals are: Estudos Econômicos, Pesquisa e Planejamento Econômico, Revista Brasileira de Economia, Revista de Economia Politica and Revista de Econometria. These journals are ranked A in the CAPES' list of economic journals (see Faria, 2004, for a critical evaluation of the CAPES' list). 
focuses on the determinants of the number of references made to foreign references in general and to papers published in English in international journals in particular.

The reason for paying special attention to papers published in English in international journals lies on the fact that the cutting edge research in economics is published in the top journals of the field and all of them are international journals published in English. As a consequence, it is natural to study the citation pattern of Brazilian economists by analyzing the determinants of the citation of foreign and English references by them.

The years 1994 and 2004 were chosen because in the period between them important structural changes took place affecting the way research in economics is done in Brazil. The main three reasons for this choice are the following. First, there is anecdotal evidence that after the middle of the 1990's there was a sharp increase in the use of the internet in economics research. New sites such as Econpapers, SSRN, WoPEc and others put working papers on line. New electronic journals, such as the Economics Bulletin, were created. In addition, the main publishers of economic journals, Elsevier and Blackwell included, disposed their journals in electronic form. All these innovations associated with the internet reduced the search costs of economic research, since it increased the speed of finding, copying and reading economic papers. ${ }^{5}$ The second important reason is a consequence of the use of the internet as a research tool. The access to electronic resources in economics presumably increased the exposure of international literature to Brazilian researchers.

The third reason for choosing these years is that the number of graduate courses and therefore the number of graduate students in economics in Brazil also increased during the second part of the 1990's and the beginning of this new century. ANPEC's membership increased with the affiliation of new centers such as the Universidade Catolica de Brasilia and Universidade Federal de Uberlândia, among others, that opened graduate courses in economics. Besides increasing the number of graduate students, these universities increased the number of professors and researchers necessary to meet the needs and government requirements of their graduate courses.

In order to understand the determinants of the citation practices of Brazilian economists, this paper presents a model in which the representative agent is a citation seeking researcher. The solution of the model shows that citation practices of researchers are influenced by the following variables: number of co-authors; the size of the paper given by the number of pages; the affiliation of the authors; the research topic; the methodology adopted by the paper; the number of papers already published by the

5 For issues related to the impact of the internet on economic research see, among others, Bergstrom and Bergstrom (2004); Goel (2003); Wallis and Dollery (1993). 
authors; the authors' impatience; the number of self-citations, and the number of citations of articles authored by the editor of the journal. Some of these variables also appear to be relevant to explain the research productivity of scholars. ${ }^{6}$

The theoretical model is tested econometrically and we find that international references made by Brazilian economists are negatively affected by citations of journal editors' works. The empirical results also suggest that longer technical papers that do not deal with the economic history of Brazil make international citations more frequently.

The paper proceeds as follows. Section 1 presents the model of the representative citation seeking researcher. Data description and econometric tests of the predictions of the theoretical model appear in Section 2. Last Section concludes.

\section{THE MODEL}

The objective of the representative author is to impact the literature, which is given by the number of citations of his papers in the literature $(c)$. In this sense, the representative agent is a citation seeking researcher. ${ }^{7}$ However, the author does not control the number of citations of his work. This is determined by the market of ideas and depends on a variety of forces beyond an author's control.

Among the forces that determine the evolution of the citations of an author by the literature $(\dot{c})$ are: 1$)$ the reputation of the journal where his work appears $(R)$, other things equal, the greater the journal's reputation the more likely it is to be read and cited in the literature; 2 ) the number of papers already published $(q)$ by the author, which makes his work more noticeable in the literature; 3) the author's knowledge of the literature, which allows him to identify the most important problems to work on and to tackle them competently, making it easier to impact the literature. This variable is captured by the number of citations of the literature $(\chi)$.

Therefore, the evolution of the number of an author's citations in the literature is:

$$
\dot{c}=g(c, R, q, \chi)
$$

6 This holds true at least empirically. Maske et al. (2003) show that years of experience, coauthorship rates, gender, research-teaching orientation of the respondent's institution, and teaching loads are determinants of the articles produced by male and female economists.

7 According to Griliches and Einav (1998) an author's citations by the literature is a better measure of academic achievement than the number of pages of papers published in top journals. 
The author's knowledge of the literature is costly. It takes time and effort to read and understand the literature, to identify problems and to make an original and enduring contribution. This cost appears in the author's instantaneous net benefit function $U$. Of course, the author derives a positive utility from citations of his own work. As a result, the instantaneous net benefit function is postulated to assume the following form: $U(c, \chi)=\alpha f(\bar{Q}) \ln c-\Psi(\chi)$. The term $\Psi(\chi)$ corresponds to quadratic costs: $\Psi(\chi)=\chi^{2} / 2$. The function $f(\bar{Q})$ encompasses many dimensions of one's particular paper itself, where the characteristics of an author's paper are represented by $\bar{Q}$, which is a vector of variables that may include the number of pages and co-authors, the affiliation of the authors, the topic of the paper, the mathematical and econometric methodologies of the paper, etc.

The author's problem is to maximize the integral of discounted net benefit subject to the way the literature cites his work:

$$
\operatorname{Max}_{\chi} \int_{0}^{\infty} U(c, \chi) e^{-\rho t} d t
$$

subject to $\dot{c}=g(c, R, q, \chi), c_{0}$ given

where $\rho$ is the author's rate of time preference [impatience]. Notice that the control variable in this problem is the number of citations of the literature made by the representative author $\chi$.

In order to solve the model we need to make the function $g$ explicit. Without loss of generality and in line with Faria (2005) model, let us assume the function $g$ to be given by: $g(c, R, q, \chi)=a \chi+b q R-c$.

The Hamiltonian corresponding to the author's problem is:

$$
H=\alpha f(\bar{Q}) \ln c-\frac{\chi^{2}}{2}+\lambda[a \chi+b q R-c]
$$

where $\lambda$ is the costate variable associated with $c$. The first order conditions are the following:

$$
H_{\chi}=0 \Rightarrow-\chi+\lambda a=0
$$




$$
\dot{\lambda}-\rho \lambda=-H_{c} \Rightarrow \dot{\lambda}-\rho \lambda=-\left(\frac{\alpha f(\bar{Q})}{c}-\lambda\right)
$$

plus the transversality condition.

In order to find the steady state solution of this model we make $\dot{\lambda}=\dot{c}=0$ and consider eq. (1) :

$$
\begin{aligned}
& c=a \chi+b q R \\
& \lambda[1+\rho]=\frac{\alpha f(\bar{Q})}{c} \\
& \chi=\lambda a
\end{aligned}
$$

By solving these equations for the endogenous variables $c, \chi$ and $\lambda$ yields the steady state solutions below [denoted by an asterisk]:

$$
\begin{aligned}
& \chi^{*}=\frac{-[b q R]+\left\{[b q R]^{2}+4 a^{2} \alpha f(\bar{Q}) /(1+\rho)\right\}^{1 / 2}}{2 a} \\
& \lambda^{*}=\frac{\chi^{*}}{a} \\
& c^{*}=\frac{\alpha f(\bar{Q})}{\lambda *(1+\rho)}
\end{aligned}
$$

The above long run equilibrium has interesting characteristics. First, notice from equations (6)-(8) that there is a trade-off between the optimal levels of $c$ and $\chi$ :

$$
c^{*}=\frac{a \alpha f(\bar{Q})}{\chi^{*}(1+\rho)}
$$

According to equation (9), the citations of an author by the literature (c) decrease with the total number of citations $(\chi)$. As a consequence, if the size of the literature incre- 
ases, it is expected that the number of citations of a given author relative to the literature decreases: $\frac{d\left(c^{*} / \chi^{*}\right)}{d \chi^{*}}=\frac{-2 a \alpha f(\bar{Q})}{\chi^{* 3}(1+\rho)}<0$

Second, one can see that the relationship between the representative author citation practices, $\chi$, and each characteristics $Q_{i}$ of the author's paper in the vector $\bar{Q}$, is nonlinear:

$$
\frac{d \chi^{*}}{d Q_{i}} \leq 0 \Leftrightarrow \frac{\partial f(\bar{Q})>}{\partial Q_{i}} \leq 0
$$

Third, one can see that the marginal impact of the number of papers already published by the author $(q)$ and journal's reputation $(R)$ on $\chi^{*}$ is negative.

Fourth, as expected, author's impatience $(\rho)$ makes him less willing to cite the literature, since citing the literature presumes that the author spends time and effort searching, reading, understanding and thinking about it: $\frac{d \chi^{*}}{d \rho}<0$. The impact of parameters $a$ [the marginal impact of overall citations on the evolution of an author's citations] and $\alpha$ [author's tastes] on $\chi^{*}$ are positive. Concerning $c^{*}, a$ and $\alpha$ are positively related to $c^{*}$, while $\rho$ has a negative impact.

In order to test this model empirically one has to make the vector $\bar{Q}$ - which captures the quality of an author's paper - explicit. Let us consider the following list of characteristics: the number of pages $Q_{1}$, the number of authors $Q_{2}$, authors' affiliation $Q_{3}$, paper's topic $Q_{4}$, paper's methodology $Q_{5}$. Author's tastes $(\alpha)$ can be multidimensional as well, here we consider that author's tastes is a vector $\alpha=\left[\begin{array}{ll}\alpha 1 & \alpha 2\end{array}\right]$, where $\alpha 1$ is the number of self-citations and $\alpha 2$ is the number of citations of articles authored by the editor of the journal. Finally, without loss of generality we assume $a=1$.

Therefore the steady state solution of the model shows the determinants of the representative author's citation practices $(\chi)$ and the citations of his work by the literature (c). The determinants of these variables are the following: the number of co-authors; the number of pages; the affiliation of the authors'; the research topic; the methodology adopted by the paper; the number of papers already published by the authors; the authors' impatience; the number of self-citations, and the number of citations of articles authored by the editor of the journal. 
The next section tests the predictions of this model for the citation practices of an author $(\chi)$. The baseline linear empirical equation to be estimated, derived from the model, is the following:

$$
\chi=\beta_{0}+\beta_{1} Q_{1}+\beta_{2} Q_{2}+\beta_{3} Q_{3}+\beta_{4} Q_{4}+\beta_{5} Q_{5}+\beta_{6} R+\beta_{7} \alpha_{1}+\beta_{8} \alpha_{2}+\beta_{9} q+\beta_{10} \rho+\varepsilon
$$

where $\varepsilon$ is the error term.

According to the model the only $\beta$ with non-ambiguous expected signal is $\beta_{10}<0$, all other can either be positive or negative due to the non-linearity of the original function (6).

\section{DATA DESCRIPTION AND EMPIRICAL RESULTS}

The data are from 358 authors of 229 articles published in 1994 (150 authors and 116 articles) and 2004 (208 authors and 113 articles) in the top five Brazilian journals in economics: ${ }^{8}$ Estudos Econômicos [EE] (43 articles), Pesquisa e Planejamento Econômico [PPE] (32 articles), Revista Brasileira de Economia [RBE] (58 articles), Revista de Economia Politica [REP] (79 articles), and Revista de Econometria [RE] (17 articles).

The collected data for each article is the following: $\chi=$ number of foreign references (and the number of English references in international Journals); $Q_{1}=$ number of authors; $Q_{2}=$ number of pages; $Q_{3}=$ authors' affiliation; $Q_{4}=$ paper's topic; $Q_{5}=$ paper's methodology; $q=$ number of papers already published by the author(s); $\rho=$ author's rate of time preference; $\alpha \mathrm{l}=$ number of self-citations; $\alpha 2=$ number of citations of works authored by the editor of the journal.

Concerning the endogenous variable $\chi$, in the theoretical model it stands for the number of citations of the literature made by the representative author, which captures the citation pattern of an author. Here we focus only on international references. This variable is measured in two different ways. The first measure is the number of foreign references which refers to all non-Portuguese references in a given article, which includes books, book chapters, working papers, and unpublished papers in languages other than Portuguese. The second measure for $\chi$ is the number of English references in Journals, i.e., the number of citations of papers published in English in international journals.

Regarding the exogenous variables of the model, the variable $Q_{3}$ is a dummy variable where 0 corresponds to authors' affiliation outside the cities of Rio de Janeiro and São Paulo (RJ-SP) and 1 for authors' (at least one of them) affiliated with institutions

8 These are the top five journals according to the CAPES rankings. See Azzoni (2000) for an alternative journal ranking based on Brazilian publications and citations. 
located in RJ-SP. This variable captures the role of the main research centers in economics in Brazil which are presumably located in the cities of Rio de Janeiro and São Paulo. Regarding the variable $Q_{4}$, it is a dummy variable where 0 corresponds to papers on the economic history of Brazil and 1 for papers dealing with other subjects. The variable $Q_{5}$ is a dummy variable where 0 corresponds to papers with descriptive analysis, characterized by the absence of the use of technical tools (such as mathematical models and/or statistical and econometric methods), and 1 for technical papers, i.e., papers that use mathematical models and/or statistical and econometric methods.

The variable $q$ is the total number of articles, published or not, by the first author (if the paper has multiple authors). The author's rate of time preference $\rho$ is measured by the number of years since the first author of the paper (if the paper has multiple authors) received his Ph.D. degree. It is hypothesized here that older authors (as measured in terms of the number of years with a Ph.D. degree) have lower rate of time preference in comparison with younger authors. This comes as a result of experience in dealing with the publishing game. Both variables are collected from the Lattes' curriculum of each author.

TABLE 1 - FOREIGN REFERENCES JOURNALS/YEARS (1994/2004)

\begin{tabular}{lcccccc}
\hline yearljournal & all & RBE & REP & PPE & EE & RE \\
\hline all & 63.49 & 67.83 & 60.80 & 67.29 & 53.79 & 78.23 \\
1994 & 59.15 & 64.73 & 56.13 & 72.71 & 34.37 & 77.71 \\
2004 & 67.90 & 71.98 & 66.00 & 61.14 & 66.49 & 78.60 \\
growth rate \% & 14.80 & 11.21 & 17.58 & -15.92 & 93.45 & 1.15 \\
\hline
\end{tabular}

TABLE 2 - ENGLISH REFERENCES JOURNALS/YEARS (1994/2004)

\begin{tabular}{lcccccc}
\hline year/journal & all & RBE & REP & PPE & EE & RE \\
\hline all & 27.58 & 34.27 & 19.09 & 33.49 & 22.40 & 44.54 \\
1994 & 22.69 & 27.92 & 18.36 & 29.06 & 11.73 & 34.07 \\
2004 & 32.56 & 42.73 & 19.89 & 38.52 & 29.38 & 51.87 \\
growth rate \% & 43.51 & 53.08 & 8.31 & 32.54 & 150.54 & 52.26 \\
\hline
\end{tabular}

Tables 1 and 2 present the descriptive statistics for the endogenous variable $\chi$. When measured as foreign references the data show for the overall sample of journals that the proportion of foreign references to total references increased from 59\% in 1994 to $68 \%$ in 2004 , with a growth rate of $15 \%$. The only journal that shows a decrease during this period is PPE. The journal that presents the highest growth rate, $94 \%$, is EE. When the endogenous variable $\chi$ is measured as English references, we have for all journals that $23 \%$ of the total references were English references in 1994, this 
proportion increased to $33 \%$ in 2004 , with a growth rate of $43 \%$. Each one of the journals shows an increase, with EE with the highest rate of growth. The raise in the number of international citations is indicative of an increase in the degree of openness of research in economics made in Brazil. In other words, Brazilian economists are becoming more influenced by international literature.

Table 3 presents the descriptive statistics for the remainder exogenous variables. The number of authors $\left(Q_{1}\right)$ increased from 1.29 per article in 1994 to 1.84 in 2004, with a growth rate of $43 \%$. This is in line with the reported international trend that the number of co-authored papers in economics has been on the rise over time (e.g., Sutter and Kocher, 2004). One of the explanations for this fact lies on the increasing specialization in our field. Regarding the average number of pages $\left(Q_{2}\right)$ per article it also has been in the rising, in 1994 the average size was 20 pages, it increased to 24 pages in 2004, with a growth rate of $20 \%$.

\section{TABLE 3}

\begin{tabular}{lrrr}
\hline VARIABLE & 1994 & 2004 & GROWTH RATE \\
\hline$Q_{1}$ & 1.29 & 1.84 & $43 \%$ \\
$Q_{2}$ & 20.48 & 24.48 & $20 \%$ \\
$\alpha 1$ & 1.65 & 1.86 & $13 \%$ \\
$\alpha 2$ & 0.05 & 0.125 & $150 \%$ \\
$Q$ & 10.05 & 17.6 & $75 \%$ \\
$\rho$ & 10.1 & 8.34 & $-17 \%$ \\
Technical paper & 0.65 & 0.84 & $28 \%$ \\
Descriptive analysis & 0.35 & 0.16 & $-53 \%$ \\
Eco. history of Brazil & 0.12 & 0.07 & $-41 \%$ \\
Other topics & 0.88 & 0.93 & $22 \%$ \\
RJ-SP affiliation & 0.67 & 0.57 & $-15 \%$ \\
Other affiliation & 0.33 & 0.43 & $30 \%$ \\
\hline
\end{tabular}

The number of self-citations $(\alpha \mathrm{l})$ increased from 1.65 in 1994 to 1.86 in 2004, with a growth rate of $13 \%$. The number of citations of articles authored by the editor of the journal $(\alpha 2)$ has risen from 0.05 in 1994 to 0.125 in 2004, with a growth rate of $150 \%$. The total number of papers by the first author $(q)$ increased from 10.05 in 1994 to 17.6 in 2004 , with a growth rate of $75 \%$. The number of years since the first author of the paper [if the paper has multiple authors] received his Ph.D. degree, the variable $(\rho)$, decreased from 10.1 in 1994 to 8.34 in 2004, with a negative growth rate of $17 \%$.

Taking the topics of the published papers $\left(Q_{4}\right)$ into account, there is a sharp decline in the number of papers published on the economic history of Brazil, more specifically, in 1994 12\% of the papers were about the Economic history of Brazil and in 2004 this proportion reduced to $7 \%$, with a negative growth rate of $41 \%$. Regarding the methodology of the papers $\left(Q_{5}\right)$, in $199465 \%$ of the published papers used math- 
ematical models and/or statistical and econometric methods, this proportion increased to $84 \%$ in 2004 , with a rate of growth of $28 \%$. These figures suggest that economists in Brazil are becoming more technically oriented ${ }^{9}$ and more diversified in terms of topics chosen for investigation.

Another important trend showed by the data is the reduction of the number of papers published by authors affiliated with institutions located in Rio de Janeiro and São Paulo. The proportion of papers published in 1994 by authors in RJ-SP is 67\% and this proportion reduces to $57 \%$ in 2004 , with a negative growth rate of $15 \%$. This shows that the economics research in Brazil is becoming more widespread geographically. One of the reasons for this is the opening of new graduate programs in economics in universities outside RJ-SP. ${ }^{10}$

The baseline linear equation for the citation pattern of international literature by Brazilian economists derived in the theoretical model is the following:

$$
\chi=\beta_{0}+\beta_{1} Q_{1}+\beta_{2} Q_{2}+\beta_{3} Q_{3}+\beta_{4} Q_{4}+\beta_{5} Q_{5}+\beta_{6} R+\beta_{7} \alpha_{1}+\beta_{8} \alpha_{2}+\beta_{9} q+\beta_{10} \rho+\varepsilon
$$

Notice, however, that we must remove the variables $q$ and $\rho$, because of measurement problems in the data source, the Lattes' curriculum. There is a number of problems in this data source, the main problems are the following: i) many authors provide incomplete information; and ii) there are authors absent in the Lattes database. As the reputation of the journal, the variable $(R)$, is the same for all the journals examined - since all of them are considered top journals in Brazil - we also eliminated this variable from the model. In addition, we created a new dummy variable $Q_{6}$ defined as follows: $Q_{6}=0$, when $Q_{4}+Q_{5}=0$ or 1 ; and $Q_{6}=1$ when $Q_{4}+Q_{5}=2$. Thus, $Q_{6}$ captures the impact of technical papers that do not deal with the economic history of Brazil on international citations.

Given these modifications the final estimated equation is:

$$
\chi=\gamma_{0}+\gamma_{1} Q_{1}+\gamma_{2} Q_{2}+\gamma_{3} Q_{3}+\gamma_{5} \alpha_{1}+\gamma_{5} \alpha_{2}+\gamma_{6} Q_{6}+\varepsilon
$$

The model is computed for all journals and authors. We used three samples: 1994-2004 (unbalanced panel), 1994 and 2004. The results are reported in Tables 4 and 5 below.

9 This fact may be due to differences between generations in which the newly minted Ph.D's have better technical formation and research interests (see Faria, 2004) as well as to rhetorical conventions in economics. Technical knowledge decreases the opportunity cost of a contributor who has acquired the minimal technical expertise demanded by the journal. (Wallis and Dollery, 1993). In addition, it makes it easier for a referee to evaluate an article. However, as stressed by Frey (2001), the emphasis on formalism may lead to a disregard for relevance and originality.

10 For international trends on economic research see Coupé (2004). 


\section{TABLE 4}

\begin{tabular}{lccc}
\hline Dep. Var. $\chi$ (Foreign References) & $1994-2004$ & 1994 & 2004 \\
\hline Constant & 9.32 & 7.87 & 14.3 \\
& $(3.98)$ & $(2.49)$ & $(3.71)$ \\
\# self-citations $(\alpha 1)$ & 0.86 & 0.61 & 0.89 \\
& $(2.34)$ & $(0.85)$ & $(1.87)$ \\
\# of citations of editor's articles $(\alpha 2)$ & -4.18 & -8.62 & -3.32 \\
& $(-3.59)$ & $(-4.10)$ & $(-3.42)$ \\
\# of authors $(Q 1)$ & -1.54 & -0.51 & -2.66 \\
& $(-1.29)$ & $(-0.19)$ & $(-2.00)$ \\
\# of pages $(Q 2)$ & 0.23 & 0.22 & 0.27 \\
& $(2.42)$ & $(1.61)$ & $(2.27)$ \\
Author's affiliation $(Q 3)$ & -2.59 & -3.61 & -0.90 \\
& $(-1.52)$ & $(-1.31)$ & $(-0.40)$ \\
Dummy $(Q 6)$ & 4.57 & 5.36 & 0.05 \\
& $(2.63)$ & $(2.43)$ & $(0.01)$ \\
N & 225 & 114 & 111 \\
R2 adj & 0.11 & 0.10 & 0.08 \\
F & 5.63 & 3.16 & 2.69 \\
P-Value & 0.00 & 0.00 & 0.01 \\
\hline
\end{tabular}

Notes: t-statistics into parenthesis.

\section{TABLE 5}

\begin{tabular}{lccc}
\hline Dep. Var. $\chi$ (English References in Journals) & $1994-2004$ & 1994 & 2004 \\
\hline Constant & 2.11 & 3.00 & 2.91 \\
& $(1.68)$ & $(1.96)$ & $(1.32)$ \\
\# self-citations $(\alpha 1)$ & -0.02 & -0.06 & 0.01 \\
& $(-0.11)$ & $(-0.15)$ & $(0.07)$ \\
\# of citations of editor's articles $(\alpha 2)$ & -2.73 & -3.68 & -2.57 \\
& $(-4.83)$ & $(-5.44)$ & $(-4.61)$ \\
\# of authors $(Q 1)$ & -0.29 & -0.32 & -1.08 \\
& $(-0.44)$ & $(-0.21)$ & $(-1.32)$ \\
\# of pages $(Q 2)$ & 0.13 & 0.06 & 0.22 \\
& $(2.42)$ & $(1.06)$ & $(3.08)$ \\
Author's affiliation $(Q 3)$ & -0.72 & -1.14 & 0.26 \\
& $(-0.77)$ & $(-0.77)$ & $(0.20)$ \\
Dummy $(Q 6)$ & 3.84 & 3.70 & 2.24 \\
& $(4.69)$ & $(3.34)$ & $(1.67)$ \\
N & 225 & 114 & 111 \\
R2 adj & 0.12 & 0.11 & 0.12 \\
F & 6.19 & 2.37 & 3.61 \\
P-Value & 0.00 & 0.03 & 0.00 \\
\hline
\end{tabular}

Notes: t-statistics into parenthesis. 
The main empirical result of this paper is that both measures of the dependent variable, foreign references and references to journals published in English are influenced by the citations of editor's articles $(\alpha 2)$, the number of pages $\left(Q_{2}\right)$ and the dummy variable $\left(Q_{6}\right)$.

Concerning the impact of citations of editor's articles $(\alpha 2)$ on $\chi$ it is necessary to consider two possible reasons for authors to cite editors. The first explanation is that an author develops a strategy to maximize the chances of publishing a paper. The author may choose to cite the journal editor so as to influence her editorial decisions in favor of the author's paper. Another explanation, not necessarily at odds with the first one, comes from the fact that editors are generally chosen from the pool of leading researchers. As it happens they are usually highly cited and they use their leadership to shape the journals they edit according to their views and expertise. As a result, it is natural to expect editors to be cited in the journals they edit.

As the estimated impact of citations of editor's articles $(\alpha 2)$ on $\chi$ is negative this suggests that an author uses as strategy to get a paper accepted for publication the citations of the editor's work rather than the relevant international literature. This is indicative of editorial favoritism (see Berg and Faria, 2004). By considering the case Brazilian editors are in fact leading economists in their respective fields; it is rather difficult explaining why the citations of their papers negatively impact the citations of the international literature. If they are leaders in their field probably the international literature would refer to their work and vice versa and therefore any author dealing with the relevant international literature and the editor's work would cite both. As a consequence we would have a positive effect of editor's articles $(\alpha 2)$ on $\chi$.

The positive impact of $\left(Q_{2}\right)$ on $\chi$ is an expected result since the longer the paper the longer the list of references. Concerning the positive impact of the dummy variable $\left(Q_{6}\right)$ on $\chi$, it means that papers written on subjects other than economic history of Brazil that use mathematical models and/or statistical and econometric methods make more international references. This is an expected result as well, since technical papers, when updated, rely upon the cutting edge research published in international journals; in the same vein, great part of the literature on the economic history of Brazil is published in Portuguese.

Therefore, the results show that there is a negative and significant impact on international citations by references to the works authored by domestic journals editors. We also find that longer papers that deal with subjects other than the economic history of Brazil and use technical tools are more likely to make international citations. These results hold true when we extend the model by considering the number of English citations as a proportion of total number of citations, the alphas as a proportion of 
the total number of citations and include dummies for each one of the journals [these results are available from the authors upon request].

\section{CONCLUDING REMARKS}

This paper studies the determinants of international citations by Brazilian economists in papers published in the top domestic journals in the years 1994 and 2004. The citation pattern of Brazilian economists has changed between these two years in accordance with changes in the way research in economics is made in Brazil.

The main changes identified in this paper are: 1) the increase in the degree of openness of the Brazilian research, i.e., it has become more influenced by international literature; 2) increasing specialization in the profession reflected in the increase of the number of co-authored papers published; 3 ) the research is becoming more technical and more diversified in terms of topics chosen for investigation; 4) the research is becoming more widespread geographically reducing the relative importance of research centers located in Rio de Janeiro and São Paulo.

In spite of these changes, Brazilian research in economics is still plagued by old problems such as editorial favoritism, reflected in the importance of citations of domestic journals editors'. This paper finds that citations of works authored by domestic journals editors have a negative and significant impact on international citations of Brazilian economists. We also find that longer papers that study subjects other than the Economic history of Brazil and use technical tools are more likely to make international citations.

\section{REFERENCES}

Azzoni, C. R. Clássicos” da literatura economica brasileira: trabalhos e autores mais citados nas nossas revistas acadêmicas. Economia Aplicada, v. 2, n. 4, p. 771-780, out./dez. 1998.

. Desempenho das revistas e dos departamentos de economia brasileiros segundo publicações e citações recebidas no Brasil. Economia Aplicada, v. 4, n. 4 , p. $787-822$, out./dez. 2000.

. Onde vender o peixe? Repercussão das principais revistas brasileiras de Economia na virada do século. Economia Aplicada, v. 5, n. 4, p. 885-894, out./dez. 2001.

Berg, N.; Faria, J. R. We would like to thank you for publishing our paper... incidentally we cited yours too. Political Economy Working Paper 12/04, School of Social Sciences, University of Texas at Dallas, 2004. 
Bergstrom, T. C.; Bergstrom, C. T. Will open access compete away monopoly profits in journal publishing? Disponível em: http://octavia.zoology.washington.edu. 2004.

Coupé, T. Revealed performances: worldwide rankings of economists and economics departments, 1990-2000. Journal of the European Economic Association 1, p. 1309-1345, 2003.

. What do we know about ourselves? On the economics of economics. Kyklos 57, p. 197-215, 2004.

Dusansky, R.; Vernon, C. Rankings of US economics departments. Journal of Economic Perspectives, v. 12, n. 1, p. 157-170, 1998.

Faria, J. R. The research output of academic economists in Brazil. Economia Aplicada, v. 4, n. 1, p. 95-113, jan./mar. 2000.

Some reflections on incentives for publication: the case of the CAPES' list of economic journals. Economia Aplicada, v. 8, n. 4, p. 791-816, set./dez. 2004.

. The game academics play: editors versus authors. Bulletin of Economic Research 57, p. 1-12, 2005.

. Citations. In: Darity, William (Ed.), International Encyclopedia of the Social Sciences. $2^{\text {nd }}$ Edition. Mason: Thomson Gale, forthcoming, 2006.

Frey, B. Why economists disregard economic methodology. Journal of Economic Methodology 8, p. S. 41-47, 2001.

Garcia-Castrillo, P.; Montanes, A.; Sanz-Gracia, F. A worldwide assessment of scientific production in economics (1992-1997). Applied Economics 34, p. 1453-1475, 2002.

Goel, R. K. A market mechanism for scientific communication: a comment. Kyklos 56, p. 395-400, 2003.

Griliches, Z.; Einav, L. Flawed rankings: a comment [on Dusansky-Vernon]. Journal of Economic Perspectives, v. 12, n. 4, p. 233-235, 1998.

Issler, J. V.; Pillar, T. Mensurando a produção científica internacional em economia de pesquisadores e departamentos brasileiros. Pesquisa e Planejamento Econômico 32, p. 323-381, 2002.

Issler, J. V.; Ferreira, R. C. Avaliando pesquisadores e departamentos de economia no Brasil a partir de citações internacionais. Pesquisa e Planejamento Econômico 34, p. 491-538, 2004.

Jin, J.; Yau, L. Research productivity of the economics profession in East Asia. Economic Inquiry 37, p. 706-710, 1999. 
Kalaitzidakis, P.; Mamuneas, T. P.; Stengos, T. European economics: an analysis based on publications in the core journals. European Economic Review 43, p. 1150-1168, 1999.

Lucas, R. Contributions to economics journals by the Canadian economics profession, 1981-1990. Canadian Journal of Economics 28, p. 949-960, 1995.

Maske, K. L.; Durden, G. C.; Gaynor, P. E. Determinants of scholarly productivity among male and female economists. Economic Inquiry 41, p. 555-564, 2003.

Pomfret, Richard; Wang, Liang Choon. Evaluating the research output of Australian Universities' economics departments. Australian Economic Papers 42, p. 418-441, 2003.

Rocha, C. H.; Machado, A. L. O desempenho universitário acadêmico-pedagógico versus o desempenho financeiro. Revista de Economia Contemporânea 7, p. 161-168, 2003.

Scott, L. C.; Mitias, P. M. rends in rankings of economics departments in the U.S.: an update. Economic Inquiry 34, p. 378-400, 1996.

Sutter, M.; Kocher, M. Patterns of co-authorship among economics departments in the USA. Applied Economics 36, p. 327-333, 2004.

Thursby, J. G. What do we say about ourselves and what does it mean ? Yet another look at economics department research. Journal of Economic Literature 38, p. 383-404, 2000.

Tombazos, C. G. A revisionist perspective of European research in economics. European Economic Review 49, p. 251-277, 2005.

Wallis, J. L.; Dollery, B. E. The economics of economics: a model of research discourse. Australian Economic Papers 32, p. 175-183, 1993. 